\title{
Collaborating with Nonlibrary Faculty for Assessment and Improved Instruction
}

\author{
Holt Zaugg \\ Brigham Young University - Provo, holt_zaugg@byu.edu \\ Curtis Child \\ Brigham Young University - Provo, cchild@byu.edu
}

Follow this and additional works at: https://scholarsarchive.byu.edu/facpub

Part of the Library and Information Science Commons

\section{Original Publication Citation}

Holt Zaugg \& Curtis Child (2016): Collaborating with Nonlibrary Faculty for Assessment and Improved Instruction, Journal of Library Administration, DOI: 10.1080/01930826.2015.1124704

\section{BYU ScholarsArchive Citation}

Zaugg, Holt and Child, Curtis, "Collaborating with Nonlibrary Faculty for Assessment and Improved Instruction" (2016). Faculty Publications. 1632.

https://scholarsarchive.byu.edu/facpub/1632 
Collaborating with Nonlibrary Faculty for Assessment and Improved Instruction

Holt Zaugg and Curtis Child

Brigham Young University 


\begin{abstract}
Collaboration with other entities and individuals has long been a standard practice of libraries. Typically, these collaborations seek to reduce redundancies, save money, and support educational and research efforts. However, a new model of collaboration exists that both assists discipline-specific research practices and informs library procedures. This article reviews two collaborations between an assessment librarian and a sociology class. The collaborations are unique because the library is the focus of the collaboration, with sociology students being able to apply classroom learning in a real-world setting. Several suggestions are provided for best practices when endeavoring to use this type of collaboration to inform library practice and engage students in hands-on learning.

Keywords: collaboration, assessment, wayfinding, long-term analysis, qualitative analysis, interdisciplinary collaboration, real-world evaluation, library practice.
\end{abstract}

\title{
Author Notes
}

Holt Zaugg, Ph.D.

Assessment Librarian

Harold B. Lee Library

Brigham Young University

Provo, Utah

Email: holt_zaugg@byu.edu

Curtis Child, Ph.D.

Associate Professor Sociology

Brigham Young University

Provo, Utah

Email: cchild@byu.edu

Received: September 8, 2015

Accepted: November 13, 2015 


\section{Collaborating with Nonlibrary Faculty for Assessment and Improved Instruction}

How can library faculty engage in mutually productive relationships with nonlibrary faculty and students from other disciplines? We report here on one such effort that involves library personnel and an advanced undergraduate sociology class. During each of 2 semesters, the principal authors of this article — one, the university's assessment librarian, and the other, an assistant professor in the sociology department - collaborated on two evaluation projects that involved students and library patrons. The projects allowed the assessment librarian to make progress on the evaluations that are central to his job description; they were not originated for pedagogical reasons. Even so, they were pedagogically effective, because students benefited from working alongside their professor in real-world data collection and analysis efforts. The students were all part of a senior-level research methods course, so the collaboration provided a unique teaching opportunity that allowed the sociology professor to engage the students in a realworld experience. The collaboration was not without its challenges, however, so we document both the benefits and difficulties associated with this type of endeavor.

We couch this case study within a rich literature on various types of collaborations in the library context. Librarians have been interested in how they are able to augment their efforts by becoming embedded in discipline-specific instruction. The literature suggests that library collaborations can provide a multitude of positive outcomes. These outcomes include, but are not exclusive to, economic advantages, increased communication skills, improved management skills, added value to student learning, a broader view to student and faculty research, and improved personal and professional self-confidence (Al-Harrasi \& Al-Aufi, 2012; Besara \& Kinsley, 2011; Brooke, McKinney, \& Donoghue, 2013; Dilevko, 2013; Holloway, 2011; Sargent, Becker, \& Klingberg, 2011). 
This article builds on our current understanding of collaborations. To date, librarians have indicated the utility of collaborating with students and faculty. Very little research, however, documents how students and nonlibrary faculty might be used to evaluate library services. Moreover, most research on collaborations focuses on collaborations at an institutional level (e.g., between libraries, other university entities, or outside businesses) or on a personal level (i.e., between librarians and faculty or students). Our contribution highlights an integrated collaboration between the library and an advanced sociology class: a collaboration at the institutional level and at a personal level among a librarian, the teaching faculty member, and students within the class.

This article proceeds in the following way: We review the literature on collaborations within the library context. The review identifies categories of collaborations and underscores the unique qualities of each collaboration. Following this, we describe the collaboration initiated at our university and reflect on how well it worked, pointing out both the benefits and challenges. Ultimately, we argue that this collaboration serves as a model for other potential collaborations between librarians and other university entities. We conclude by offering considerations for future collaborations.

\section{Background}

The history of libraries is one of helping and collaborating. A review of the published literature involving collaborative case studies with academic libraries from 2010 to 2015 reveals two major categories of collaboration: libraries working with other entities and librarians working with specific groups of patrons. The motivations behind and the benefits derived from the collaborations are varied. At the institutional level there are three major collaboration 
partners with libraries — namely, other libraries, other university campus entities, and outside businesses. On the personal level, collaborations involve other university faculty and students.

Despite the progress made in documenting the value of collaborations, there are lesserknown ways that collaborations might benefit libraries. Specifically, while most research that addresses collaborations between librarians and faculty or students describes the benefits to the latter, little has been said about how collaborations might further the interests of the library as well. This is unfortunate, since it overlooks the opportunity that libraries have not only to help students and faculty with their research but to become sites of research in and of themselves.

Here we document the state of research on library collaborations and follow this review with an argument for making libraries not only sites that facilitate research but also sites where research actually takes place in a way that both improves library services and provides instruction to students. In most collaborations, librarians seek to provide greater access to information and library resources that benefit their co-collaborators in teaching, research, student learning, or promotion efforts.

\section{Collaborations between Academic Libraries}

The main thrust of collaboration between libraries focuses on the cost-effective delivery of services to patrons (Al-Harrasi \& Al-Aufi, 2012; Breeding, 2013; Drake, 2010; Wilson, 2012). With libraries facing increased economic constraints, collaboration becomes a method of preventing needless duplication of resources and effort. As libraries contribute to the total collection, patrons are able to access more resources for study and research. Collaborations reduce economic pressures but require negotiated agreements, especially when one collaborating institution is significantly larger or smaller than other partner institutions. 
In other cases, the collaboration takes on a mentoring role as a more established academic library assists emerging libraries to develop their faculty's and staff's skills. Leong and Nguyen (2011) describe such a collaboration between Vietnamese and Australian libraries. In this case, there was opportunity to learn from and mentor one another so that those librarians with expertise could share with those desiring greater expertise. Care and attention were given to travel and time zone issues for online workshops and training. However, determining each library's needs and expertise in advance assisted in planning for this collaboration.

\section{Collaborations with University Campus Entities}

These collaborations were as varied as the university entities involved in the collaboration. As with other libraries, there are time and economic savings to be found with these types of collaboration, especially in the planning and delivery stages (Besara \& Kinsley, 2011; Koelker, Bouchard, \& Lutz 2010; Murray, 2011). Intrauniversity collaborations provide critical feedback to determine that needs were being met in a cost-effective manner. However, other collaborations with the library were used to aid in recruiting students, especially athletes (Kopp, 2013); creating and obtaining a better understanding of library and faculty roles (Mix, 2013); altering service delivery to improve student learning and retention (Besara, \& Kinsley, 2011; Murray, 2011); promoting library or university services for students (Anderson, 2012); and soliciting funds from potential donors (Murray, 2011).

\section{Collaborations with Outside Businesses}

Collaborations with outside businesses commonly take the form of promoting library services (Grays \& Tucker, 2013), outsourcing web design and other library needs (Laster et al., 2011), or providing information services via an outside agency to assist nonuniversity patrons to move forward with business ventures (Martin, 2010). 


\section{Collaborations with Faculty}

Collaborations with faculty typically focus on identifying faculty needs and building faculty members' understanding of how librarians can contribute to and support one another (Amante, Extremeno, \& da Costa, 2013). As this perspective and trust is developed between faculty and librarians, multiple opportunities arise for librarians to become integral parts of faculty courses, including initial design, delivery, and/or final course products. Examples of successful collaborations include teaching disadvantaged students how to use the available technologies and services to increase completion and success rates (Clarke, 2012); becoming a portal to parallel research and collections to provide a broader or different approach to instruction and research (Dilevko, 2013); providing research and writing instruction using a problem-based learning approach (Hines \& Hines, 2012); assisting in curriculum development through the location and teaching of specific resources related to the course (Mazella \& Grob, 2011; Soules, Nielsen, Lee, \& Rifae, 2013); and engaging with faculty at the university council level to increase understanding of librarian and faculty needs (Mix, 2013).

These collaborations increased mutual understanding of what nonlibrary faculty and librarians could offer one another to improve the learning of students and the quality of research. They also helped to reduce redundancies in library and faculty instruction while providing additional materials and insights. Through each collaboration, trust and understanding were increased and students became the ultimate beneficiaries.

\section{Collaborations with Students}

Collaborations with students typically involve seeking student input in the design, development, and delivery of library services and programs. Recent efforts seek to engage the student in deeper and more meaningful collaborations, where students feel that they are 
providing strong direction in the strategic planning of libraries (Appleton \& Abernethy, 2013; Barratt \& White, 2010; Ellis \& Phillips, 2013).

\section{Other types of Collaborations}

Other collaborations focus on emerging areas within academic instruction-namely, connecting distance education or online students with the library (Brooke et al., 2013; Holloway, 2011). These collaborations involve increased three-way communication among students, faculty, and librarians, who are often in three separate locations. They require librarians to increase their understanding of how online students differ in needs and background from oncampus students. They also require increased flexibility in how to effectively reach out to and collaborate with these students to provide information science instruction. These collaborations enhance the instruction and learning of students.

\section{The Library as a Site of Collaborative Research}

Recent trends have more academic librarians hiring personnel with the specific assignment to evaluate library services and collections. While titles, designations, and job descriptions vary depending on the library, the task remains the same: to determine how well library services and collections are meeting patron needs. However, some assessments are quite labor intensive, requiring several researchers to collect data in a timely and efficient manner. The need for such assessments requires those in a library assessment position to seek partnerships to aid in conducting these assessments.

While each of the collaborative opportunities discussed above produces a direct benefit for libraries and their patrons, using the library and librarians as a means for real-world research collaboration is missing. The library, as a microcosm of the university, provides the opportunity for real-world experience in conducting meaningful evaluation research-research that is 
beneficial both to the library and to the students who are developing expertise in research activities.

\section{The Sociology-Harold B. Lee Library Collaboration}

The sociology-library collaborations that we report here took place during the 2014-2015 academic year, with each class in each semester working on its own project. Students were part of a one-semester course titled Qualitative Research Methods, which fulfills a requirement for sociology majors and is one of two courses that provide advanced training in research methods. As the name implies, the course introduces students to the epistemology and methodology of qualitative research by covering research design, data collection, and data analysis for specifically qualitative research projects (e.g., fieldwork and ethnography, interview-based studies, focus groups). During a typical semester, students learn and practice qualitative research skills and then apply them in small-scale, student-led research projects.

One sociology professor and 41 of his undergraduate students participated in the collaboration. Fourteen students were enrolled during the fall semester of 2014, and 27 students were enrolled in the winter semester of 2015. Most of the students were sociology majors, and nearly all of them seniors. The majority of the students were female (59\%).

On the library side of the collaboration, the Assessment Office at the Harold B. Lee Library (HBLL) is responsible for the evaluation of library services and products and the efficacy of their delivery to library patrons. The office either conducts assessments or supports other librarians in assessing library services, products, and delivery on a regular basis. These evaluations range from national surveys (e.g., LibQUAL ${ }^{+\circledR}$, MISO) to local assessments of library interests. The office's collaborations with faculty and students provide real-world 
learning opportunities while conducting complicated assessments that require a great deal of manpower.

The HBLL Assessment Office has a long history of collaborating with academic departments at the university (Washburn \& Bibb, 2011; Zaugg et al., 2015a; Zaugg et al., 2015b). Librarian contacts with the Sociology Department identified potential faculty partners and each faculty member was approached with a potential collaboration project. Two sociology faculty members, one who teaches a quantitative methods course and another who teaches a qualitative methods course, agreed to the collaboration. This paper focuses on the collaboration with the sociology professor with a qualitative focus.

\section{Weighing the Costs and Benefits of Collaborating}

First, we document the perceived benefits and challenges of the collaboration from the perspectives of the sociology instructor and the assessment librarian based on their perspectives before the collaboration took place. We discuss them here in order to show the full range of experiences regarding the collaboration that represents the two perspectives of the collaborators.

\section{The Sociology Professor's Perspective}

When invited to participate in the collaboration, three primary concerns presented themselves to the sociology faculty member: First, his course was already working well. The instructor had taught it multiple times previously—consistently since 2012 - with positive student reviews. Besides liking the class generally, students especially enjoyed the studentdriven research projects. For the most part, these were projects that the students chose on their own and worked on in groups that they selected themselves. When the instructor informed some of his former students of the possibility of collaborating with the library on a research project, the students warned him that doing so was not a good idea if it meant abandoning the student-led 
projects. Moreover, they felt like working with the library was sure to induce boredom in future classes.

The second major concern for the sociology professor was that it would be difficult to manage the course, because "real" research projects are unpredictable in many ways. In terms of simply creating a schedule for the course, it is a challenge to know how long various stages of the research will take and to anticipate how the work might need to be divided among students. It is true that these issues are present in research that takes place outside of a classroom setting, but in these cases the research is not necessarily bound to the ebb and flow of a semester-length class.

The third major concern was that, in taking on the library project, the class, and the instructor in particular, would open itself to an external stakeholder: the library. Whereas in a conventional course all activities, assignments, and due dates are negotiated between the instructor and students, who meet together frequently in a fairly private setting, the students and instructor would now be jointly accountable to a separate entity, one with its own timetable and purposes for getting the research done. Admittedly, the pressure that this creates is felt most by the instructor, whose name will go on the report and whose students' performance will potentially become a basis for improving or hurting his reputation on campus.

The anticipated benefits of the collaboration, of course, corresponded in many ways to these concerns. Thus, although the course was already going well, there was ample room for improvement. And the advantages to the students of being able to work with an external stakeholder outweighed the uncertainty in classroom management that the instructor would need to endure. After all, the professor understood that most of the students would never become professional, PhD-level sociologists. If they used any research skills in a real-world setting, then 
it would likely be for doing projects like these. It was for these reasons that the sociology instructor ultimately agreed to the collaboration.

\section{The Assessment Librarian's Perspective}

The largest challenge to this type of collaboration is building and maintaining trust between the librarian and the faculty member. Each has specific needs and goals. While there is considerable overlap, both are concerned about the quality of learning the students will receive and the quality of the final product. Similar to the sociology professor, the assessment librarian must undergo tenure and advancement evaluations. The quality of assessments and relationships with colleagues is critical to this process. Additionally, the needs of the library must meet the needs of the class and be a good match for both. In spite of these concerns, there were several perceived advantages to this type of collaboration.

Library evaluation studies often require labor-intensive data collection and analysis that would be difficult, if not impossible, without additional help. Collaborating with students as part of a course project enables assessment projects to move forward at a pace and scale that would not be possible otherwise. The collaboration provides additional insights into the design, data collection, and analysis of the study. The assessment librarian and sociology professor assist and learn from each other in the design of the research project. Students are able to see and better understand these issues and the struggle required to design good evaluations. In this sense, both faculty members are "in the trenches" with the students. This provides stronger mentoring opportunities and relationships.

Besides these obvious benefits, students gain a new perspective and appreciation for the library. They often spend more time in a wider variety of areas of the library or read material relating to the library, experiences that provide a more global picture of what the library has to 
offer the university community. In this regard, the collaboration becomes an outreach program that highlights how the library can benefit students.

Finally, the library's purpose for existing is to assist and support the teaching and research activities of faculty and students. These assessment collaborations accomplish both goals. They provide a real-world experience collecting and/or analyzing data that has a functional purpose. Faculty have the opportunity to engage students as researchers. Students have the opportunity to increase their awareness and experience in their specific field. Librarians are able to provide the assistance that is part of their mandate while meeting other job-specific requirements.

\section{The Collaborations}

The library assessment office and sociology classes thus embarked on two collaborations. For each one described below, we identify the research setting, the research question, and the role, respectively, of the library and the sociology classes. The first collaboration involved an evaluation of LibQUAL+® survey data. The second collaboration was a wayfinding study (Mandel, 2013; Sugie, 2013) used to evaluate how well students were able to find library resources, services, and employees.

\section{LibQUAL $^{+\circledR}$}

The fall 2014 collaboration focused on evaluating LibQUAL+® survey data. The LibQUAL+® survey is widely used throughout the world to determine patron perceptions of library service, ease of access to information, and physical space. It uses a mixed-method approach, asking sets of Likert-scale questions followed by an open-ended response section. Survey results are used to gauge the efficacy of library operations and to provide insights for strategic planning. The HBLL has administered the LibQUAL+® survey biennially since 2003. 
Each survey administration provided ample open-ended comments from patrons regarding HBLL operations. The repeated collection of these comments enables the library to identify and examine trends over time.

\section{Research Question.}

What trends and patterns emerge regarding the operations of the HBLL from the examination of the LibQUAL+®-survey's open-ended comments over the past 10 years?

\section{Role of the Library}

In this study, the library took on the role of a client of the sociology class and provided background to the study. The assessment librarian explained why and how the library collected the data and how the data had been used in the past. He also expressed the limitations to the data and his expectations for the ensuing analysis. After doing so, students asked questions to help clarify their roles and responsibilities. These responsibilities included completing Institutional Review Board training and complying with the standards of a researcher. Because of time constraints, the library staff helped organize the data by year and removed any identifiers. Finally, the assessment librarian and professor sought to convey that this was not a contrived class exercise but that it would be presented to, discussed with, and valued by the library leadership. This sense of importance raised the bar of classroom performance and interest.

\section{Role of the Sociology Class}

Before the students could start working with the LibQUAL+® data, it was important that they develop an understanding of qualitative research generally. This took place in the first 3 weeks of the semester, during which time the class explored with the instructor the unique epistemology of qualitative research and how it is distinguishable from more conventional quantitative research. Over the course of the next 4 weeks, students worked on developing their 
skills in making observations, interviewing in a one-on-one setting, conducting focus groups, and analyzing qualitative data. Finally, during Week 8, the class started working in earnest on the library research project. The assessment librarian visited the class for the first time. He explained his role in the library, gave some background on the LibQUAL+® dataset, articulated what kind of report he was hoping to receive from the class, and answered questions. Following this introduction to the data, the analysis continued until Week 12, at which point the students presented their research to the library administration. The remaining 3 weeks of the semester were devoted to individual papers based on student-driven research projects that did not involve the use of LibQUAL+® data.

The dataset came in the form of a spreadsheet with slightly fewer than 4,000 rows of data. Each row included information about the individual who completed the survey, including the year of the survey, the respondent's status at the university, discipline, age, and sex. Most importantly, each row also contained the full text that the respondent had entered in response to the prompt, "Please enter any comments about library services in the box below." These comments were the focus of the analysis.

The task for the class was to take this copious amount of data and to synthesize it in a way that was useful to the library. First, they familiarized themselves with the data by simply reading through large sets of responses and discussing their impressions of patterns and trends. Next, the class members and the professor inductively developed categories by which the comments could be organized. For example, some open-ended comments made reference to staff and others to the physical building, and so on. Moreover, each comment was categorized, or coded, by affect - that is, whether it was negative, positive, mixed, or ambiguous in tone. Coding 
rules based on these and other aspects of the data were formalized into a coding guide, and the students then started the process of working through the entire dataset systematically.

Once the data were coded, students divided into four teams. Some students checked on the quality of the coding, ensuring that the different coders were consistent in their efforts to categorize the data. Another group of students read (or reread) the comments by code topic in order to develop an in-depth understanding of what the survey respondents had to say about each particular issue. The students produced a narrative summary of what they learned, which was then used as the basis for the language that would make it into the final report. A third group of students used the coded data to analyze trends over time and across different groups (discipline, sex, etc.). They produced figures that showed how feelings about the particular areas of focus changed, if at all, over time. For instance, they were able to show that comments about staff went from lower than $50 \%$ positive in 2003 to nearly $70 \%$ positive in 2013 . These figures were placed alongside the narrative in the final report. A fourth group worked on collating the material and placing it into a final report as well as preparing the presentation for the library administration.

With the instructor facilitating the discussion, the students started their work by creating a calendar of deadlines, some imposed by the client but most internal to the class. The class met in a computer lab on campus, where students had the freedom to move around, to work in small groups as needed, and to discuss matters with each other and the instructor. The instructor had access to a tech podium, so the data could be projected easily onto large screens at the front of the classroom. Much of the work was completed during class time, when the students and the instructor coordinated activities, troubleshot problems, and planned next steps. Working alongside the students, the instructor took the opportunity to help the students understand the research process, as multiple issues presented themselves organically: how to systematically 
assess messy data, how to calibrate different researchers' understandings, how to deal with missing or conflicting data, how to present data in an understandable way, and so on.

During the final week of project work, four students, elected by their classmates, presented the report to the top library administrators, including the university librarian. The instructor and assessment librarian attended the meeting but assumed the role of audience members and intentionally avoided introducing the students and fielding questions from the library staff in attendance.

\section{Wayfinding}

The winter 2015 collaboration involved a library wayfinding study. Wayfinding research is especially relevant in libraries, like the HBLL, that are large and complex. The HBLL comprises an area equivalent to 11 football fields across six floors. Two additions to the library first doubled and then increased by a third the overall size of the library. While the additions added more space to the library, they also increased the complexity associated with finding library employees, products, or services located on the premises. Although the library has taken great efforts to aid patrons as they move from point A to point B in the building (e.g., there are over 10,000 signs in patron-accessible spaces with multiple maps on each floor), some patrons continue to find navigation within the library a daunting and intimidating task. Thus, this research study focused on finding the pathway successes and failures within the library for freshmen and senior students.

Research questions. Three research questions guided this analysis.

1. What were the pathway success and failure points within the HBLL?

2. What were key differences in the strategies used by the novice and expert groups of patrons? 
3. What heuristics would help to identify pathways to new or moved HBLL services?

Role of the library. As with the previous collaboration, the assessment librarian provided background material for understanding the need for this study, documentation of previous research, the expectations of and parameters for the research, and the importance this study carried with the library leadership. Unlike the previous study, in this case the assessment librarian worked closely with the faculty member on the design and implementation of the study. The sociology professor and assessment librarian shared ideas, critiqued plans, and collaborated on a design that would meet library needs and provide a promising class project. Their collaboration not only improved the study design but also increased student interest as the faculty member discussed the study design with his students. During data collection, both faculty were present to help resolve any data collection issues and to assist students as they collected data.

Role of the sociology class. As in the preceding semester, the students learned the basic epistemology and methodology of qualitative research before formally launching the wayfinding study. This was especially critical because the wayfinding study would involve not only data analysis but also data collection. Accordingly, the first 7 weeks of the semester covered the craft of qualitative research. Weeks 8 to 13 were devoted to the wayfinding project, and during the remaining weeks (14 and 15), the students worked on individual projects that did not involve wayfinding data.

Data collection for the wayfinding project took place in the following way. First, the assessment librarian obtained a random sample of freshmen and senior students from a pool of names the university provides the library for assessment needs each semester. He then sent email invitations to the students on the list, and members of the sociology class followed up with those who agreed to participate. Research participants met with members of the research team during 
one of three sessions, during which times participants were matched with a small subset of the research team. These researchers provided participants with a predefined list of library items to find (books, services, rooms, etc.) and then followed each participant as he or she tried to locate each item. The researchers video recorded each finding episode, timed how long it took to locate each item, jotted field notes about the search based on the observations, and then interviewed the participants after the finding session was complete. Later, they expanded on their observational notes and transcribed the interviews. In all, the research team studied 34 participants (18 seniors and 16 freshmen) for a total of nearly 200 finding episodes.

Next, the student researchers analyzed the data. First, they examined the videos, creating a database that tabulated how many resources students relied on when searching for items, what kinds of resources they used (e.g., desk staff, maps, etc.), and whether the resource helped the participant locate the item. The student researchers computed the average times taken to locate each item, including how long students took before needing to use a resource. They created tables that rank-ordered the first resource used as well as the most commonly used resources, with comparisons between freshmen and seniors. These numeric data were supplementary to the interview and observational data that students analyzed as well. Using qualitative data analysis software, which the students had been introduced to earlier in the semester, student researchers coded interviews for themes and wrote memos on the various finds that summarized what was learned from the different sources of data. These memos formed the basis of the final report, which documented research participants' experiences locating items, identified pathway successes and failures, and made recommendations to the library. As with the LibQUAL+® study, the culminating event for the project was a presentation to top library administrators, led by the student presenters. 
Similar to the LibQUAL+® study, the wayfinding project provided ample opportunities for the instructor to teach his students. This was rarely planned in advance, as neither the professor nor his students had experience with wayfinding research or analyzing video. Instead, opportunities for learning presented themselves frequently as the instructor and students were forced to deal with thorny dilemmas and unanticipated problems. How should they deal with the low response rate for participating in the study? How could they systematically analyze video data? How might they make sure that the researchers were consistent in their coding efforts? And how should the information be transmitted to the library?

\section{Assessing the Collaborations}

This section evaluates the success of the collaborations from the perspectives of the students, the sociology professor, and the assessment librarian. Balanced out, the collaboration was a success, although it was not without its challenges. The most obvious benefits were for the students, who benefitted from a rich learning experience, and the assessment librarian, whose assessment capacity was augmented by a new labor force. The sociology professor benefitted as well in terms of being able to teach his students in a more compelling way, but this came at the price of increased time and energy devoted to teaching.

\section{The Students' Perspective}

Students in both classes spoke highly of the library collaboration in direct conversations with their professor and in their course evaluations. This was especially true for the LibQUAL+ ${ }^{\circledR}$ collaboration, where students rated the overall course at 7.8 out of 8 and indicated that over $90 \%$ of time spent in and out of the classroom was valuable-both averages well above university averages for the semester (6.7 and 81\%, respectively). Judging from their open-ended comments, students appreciated working with "real" data in a hands-on way. As one student 
explained, "I greatly appreciate the opportunity that I had to receive some real hands on experience thanks to the Library requesting our help in assessing some of their data." Another concurred, saying that the structure of the class was "unique, but very effective in teaching me new skills and techniques that I'll be able to use for years later." This was the case even though the research was demanding. "I learned so much in the course, and never expected to get so much real-world, hands on experience," one student said. "I loved the library project (even though it was a TON of work) because it really brought all of our learning together in a real world experience."

The only negative comment about collaborating with the library was that it made the class feel "a little disorganized." "But," the student conceded, "it is the nature of the class and he [the professor] tells you that upfront." The feeling that the course was disorganized was likely a result of the open-ended nature of research, discussed above. It was impossible at the outset of the collaboration to anticipate all of the contingencies that would shape the course of the project. For some students, this uncertainty is unappealing.

Although this issue was not addressed in the student evaluations, one challenge during both semesters was that it was difficult to distribute project-related tasks equitably. At times, especially toward the end of the project, only a few students were needed to put the final touches on the report. Work like this (making final layout decisions, working through the prose to establish a consistent voice, etc.) simply cannot be done well by a large group, and yet it can be time-consuming. The instructor tried to prevent feelings of resentment among the students by explaining at the outset that some students would end up putting in more time at the start of the project, some in the middle, and some in the end. Nevertheless, it is true that in both semesters, a 
core group of students ended up doing the lion's share of work during the final days of the project, and some privately expressed irritation that this was the case.

\section{The Sociology Professor's Perspective}

From the sociology instructor's point of view, there were many things to like about the collaboration. Principal among these was that the students were interested and engaged in and outside of the classroom. Moreover, working in the trenches with the students allowed for easy transmission of important concepts, since students had more than an abstract interest in learning the material. They needed to complete the project for the client, who was counting on the class.

An unexpected benefit was that having the library as the "client" reduced the natural tension that otherwise exists between professor and student. In this collaborative setting, the students and the professor work together to impress the client. No longer is it the case that the professor is asking the students to do difficult things. Instead, the professor and the students develop a mutual understanding that challenging work must be done in order to satisfy the expectations of the external stakeholder.

The collaboration was not without its drawbacks, however. Perhaps most significantly, and as anticipated, the nature of the collaboration consumed a significant amount of time and energy on the part of the instructor. This can be a challenge for faculty who work in departments with hefty research obligations. It is not possible, after prepping the course and teaching it a few times, to put it on auto-pilot, as each semester introduces a new set of issues and challenges that require fresh time devoted to figuring them out.

Besides the added time that the project required, it also consumed more emotional energy than a conventional course. This was partly because it was difficult to plan out in advance how the research would unfold. The research team did not have a good way to estimate, for example, 
how long it would take to code the wayfinding videos or to read through the thousands of LibQUAL+® comments. For this reason, it was not easy to determine in advance exactly what the class would be doing and when. So long-term planning, which usually serves to provide students and the professor with an agreed-upon idea of the course's direction, not to mention the semblance of order and control, was nearly impossible.

The collaboration also proved stressful for the professor because his name was associated a project whose results would be seen and evaluated by his peers. In a typical course, students might choose to produce poor-quality work, with a consequentially low grade from the instructor. In the context of working with the library, producing poor-quality work was not a realistic option, since the instructor was unwilling to submit a sloppy report to his colleagues. Thus he had to devote extra time and energy to bringing the report up to a standard that he approved, which may well have been a standard to which he would not typically hold his students.

In summary, from the sociology instructor's perspective, the benefits of the collaboration were mainly pedagogical, while the drawbacks were mainly practical. Based on the instructor's account and the accounts of the students, the collaboration proved to be highly successful. The downside was that this came at the cost of time and energy, neither of which are in abundant supply in a university setting.

\section{The Assessment Librarian's Perspective}

From the assessment librarian's point of view, the collaboration serves multiple positive purposes. First, it enables assessments to be done that require considerable manpower. While some assessments could be done with fewer people, they would take longer to complete or would need to be executed with less data. Second, previous assessments have indicated that when 
student researchers interview or interact with student participants, responses are more candid and open than if interviewed by a senior researcher (Washburn \& Bibb, 2011). The student-tostudent interactions in data collection enable researchers to gather more-honest and frank responses from student participants. Third, as the student researchers are also students using the library, the assessment librarian gains a different perspective on the data analysis. The analysis is framed from the view of current students who better understand the needs and perspective of the group they represent. Data which the assessment librarian may miss are noticed by student researchers as important. Fourth, the project serves as a library outreach. As students collaborate on research with the library, they are exposed to more facets of the library than they had previously noted. They gain a greater understanding of the services offered by the library and, in turn, become ambassadors for how the library can meet student needs.

Finally, working with another faculty member strengthens the design, implementation, and analysis of the assessment. The expertise of the faculty member is turned toward a specific library issue. This provides a second pair of eyes to examine and improve the study design. In turn the library and nonlibrary faculty member learn from one another and become partners. The pressure felt by the nonlibrary faculty member attaching his name to the final report is also felt by the assessment librarian. Sharing this increased responsibility ensures a stronger final report and provides an increased learning opportunity for students.

\section{Looking Forward to Future Collaborations}

There will always be assessments of library services that need to be conducted. Similarly, sociology research methods courses will always benefit from real-world applications where students can hone their research design, data collection, and analysis skills. For these reasons, we recommend this type of collaboration to librarians and faculty members, despite some of the 
challenges associated with it. Based on our experience, we offer 12 considerations for those interested in implementing similar collaborations.

\section{Time Constraints}

A successful library-sociology collaboration must involve a research project that is able to be conducted within the parameters of the semester. The length of the project should allow for the professor to present instruction that leads to collecting data, analyzing data, and presenting results. Not all projects are suited to this time frame.

\section{Research Toolkit}

The assessment should be well suited to the research methodology being taught in the class. In our case, the Qualitative Research Methods course called for a research project with a qualitative component. A course devoted to quantitative research would benefit from a project that involved analyzing quantitative data. Other collaborations may involve students honing research skills in other disciplines (e.g., anthropology, education). Whatever the methodology, it is imperative that the course instructor develop in the students the skills to correctly and adequately use the assessment tools.

\section{Involving Everyone}

Involving everyone in the collaboration, including students where possible, is valuable for methodological and pedagogical reasons. In working together, the assessment is strengthened to the extent that it is viewed and critiqued by multiple pairs of eyes. It allows the professor to "step into the trenches" with the students in the design, data collection, and analysis. In this way, the instructor is less the "sage on the stage" and more a mentor and co-collaborator. Students gain the understanding that assessments are not always tied up in a neat little package with a bow on top. 


\section{Limits to Student Involvement}

Despite the many benefits of using students in the design and implementation of the study, there are practical limits to what students can accomplish on their own. At the outset of the first collaboration, the sociology professor was committed to making the collaborative research student-driven, with all decisions subject to a democratic process of decision making. Perhaps a worthy goal in the abstract, this introduced a number of difficulties. For instance, there are countless decisions that must be made over the course of the project, and there simply is not enough time to debate them and then to decide on a direction. Moreover, students do not always have enough experience to make correct decisions and, in any case, may have interests that are at odds with the production of high-quality research. In practice, the professor and students compromised by debating many of the important issues and voting on a number of them. The professor always held veto power, but he used it sparingly.

\section{Building Trust}

A successful cross-disciplinary collaboration hinges on trust among all parties involved. The first collaboration may ultimately require a leap of faith, since little opportunity for building trust will have developed at that point. A stranger showing up at your office door seeking to collaborate on a project can be a daunting prospect for both participants. It helps if each person in the collaboration has the project and course well thought out before agreeing to join forces. Initial discussions between the assessment librarian and faculty member need to include individual and joint responsibilities and the scope of the project. There needs to be open, frank, and polite discussions leading up to and during the project. 


\section{Managing Expectations}

Although the students almost unanimously enjoyed the library collaboration, some struggled with the open-ended, adapt-as-you-go approach. Even if this aspect of doing research cannot be changed, its negative effects on students' perceptions of the course can be mollified by making it clear before the project starts that real research is not always predictable. This provides a teaching opportunity and helps to prevent feelings of frustration when the unexpected happens, as it often will.

\section{The Library as Client}

Creating a sense among the students that the library is the client has a number of benefits. It allows the instructor and students to work together in a truly collaborative way, and it provides an experience that mimics research projects in a professional setting. It may also improve student motivation to the extent that they believe the research is being counted on by stakeholders external to the class.

\section{Incentivizing Performance}

One way of incentivizing the students to treat the library as a client is to include the librarians' assessments in the students' final project grades. For example, the sociology instructor sent all librarians who attended the final presentation a survey that asked them to rate the students' performance on a number of dimensions. Students were aware that this assessment would be factored into their final grade. Along with this, students received one grade in common — a grade for the professor's assessment of the project overall — and an individual grade. The individual grade was based on an evaluation of a log that each student kept, documenting time spent on the project, as well as a written justification of the student's contribution to the project. 


\section{Class Size}

The library-sociology collaborations took place with classes of different sizes. The first collaboration included 14 students; the second included 27. Based on student comments and the instructor's impressions, the smaller class size had numerous advantages. This is because the larger the class size, the easier it is for some students to disengage from the class. Moreover, with each additional student, planning schedules, distributing work evenly, making collective decisions, and so on become more challenging. On the flip side, having class sizes that are too small does not allow the research team to take on a project of the size that is meaningful for a university library. Further research could usefully examine what size of collaborations are ideal, but we propose that classes of 10 to 15 students work best for the kind of intense collaborative research that we have described here.

\section{Collecting versus Analyzing Data}

Although we do not have a specific recommendation here, we do want to draw attention to the differences in taking on projects that just involve analyzing data and those that involve collecting data as well. The task of only analyzing data is clearly easier than both collecting and analyzing data. Many of the benefits of the collaboration can be realized if only analysis is undertaken. Moreover, many of the challenges associated with research present themselves during the data collection phase, which is often messy. That said, collecting data is exciting for students, and it allows them to see an entire research project from beginning to end.

\section{Scholarship}

As students are heavily involved in the collection and analysis of data, they deserve and claim a right to be acknowledged in subsequent conference presentations and articles. If students go directly into business, the subsequent presentations provide evidence of the importance and 
impact of the assessment. If students are planning on graduate studies, the conference presentations and articles help to promote their graduate applications because they have conducted and published research. Either scenario makes the student more marketable in future endeavors.

\section{Alternative Models}

We have introduced only two ways in which a project like this might be organized. There are other possibilities. For example, in large classes, two or more groups could write competing reports, with the best one (or both) presented to the library administrators. Or two or more groups could work on different minireports that all speak to a larger issue. Each of these alternatives might address some of the challenges associated with large classes as discussed above. For especially large projects, the collaboration might span 2 (or more) semesters. For instance, students could collect data in the fall semester that students in the subsequent semester analyze. These are not the only options, of course, and librarians and their faculty counterparts might usefully experiment with what works best in their particular settings.

\section{Conclusions}

The purpose of this paper has been to document how librarians can engage in mutually productive relationships with faculty and students from other disciplines to advance the interests not only of the faculty outside of the library but of the library itself. Most of the scholarship on library collaborations addresses how academic libraries can best serve the needs of the college or university community. The initiative we introduce, by contrast, suggests a way for librarians to continue acting as a resource to different departments on campus while also using students and faculty as a resource to improve their own work. Symbiotic relationships similar to these collaborations provide an additional source of library and nonlibrary scholarship. It promotes a 
greater understanding and trust between the library and nonlibrary entities. This article represents an effort to begin the process of documenting, diagnosing, and developing best practices for this kind of collaborative research. 


\section{References}

Al-Harrasi, N., \& Al-Aufi, A. (2012). The potential of inter-state collaboration for Omani academic libraries. Library Review, 61(4), 240-260. doi:10.1108/00242531211267554

Amante, M. J., Extremeno, A. I., \& da Costa, A. F. (2013). Modelling variables that contribute to faculty willingness to collaborate with librarians: The case of the University Institute of Lisbon (ISCTE-IUL), Portugal. Journal of Librarianship and Information Science, 45(2), 91-102. doi:10.1177/0961000612457105

Anderson, C. L. (2012). LibraryPalooza: A marketing case study. New Library World, 113(1/2), 55-64. doi:10.1108/03074801211199040

Appleton, L., \& Abernethy, P. (2013). We said ... we did!: A partnership approach to developing library and student support services. New Review of Academic Librarianship, 19(2), 208220. doi:10.1080/13614533.2013.800766

Barratt, C. C., \& White, E. (2010). Case study for a large research institution library: The University of Georgia's Miller Learning Center. Journal of Library Administration, 50(2), 135-144. doi:10.1080/01930820903454977

Besara, R., \& Kinsley, K. (2011). Academic libraries—measuring up: Assessment and collaboration for student success. New Library World, 112(9/10), 416-424. doi:10.1108/03074801111182012

Breeding, M. (2013). Resource sharing in libraries: Concepts, products, technologies, and trends. Library Technology Reports, 49(1), 30-31.

Brooke, C., McKinney, P., \& Donoghue, A. (2013). Provision of distance learner support services at U.K. universities: Identification of best practice and institutional case study. Library Trends, 61(3), 613-635. doi:10.1353/lib.2013.0003 
Clarke, J. H. (2012). Partnering with IT to help disadvantaged students achieve academic success. Public Services Quarterly, 8(3), 208-226. doi:10.1080/15228959.2012.702597

Grays, L., \& Tucker, J. C. (2013). Vendor of the month: A marketing collaboration. Collaborative Librarianship, 5(2), 137-144.

Dilevko, J. (2013). The southern agrarians: A case study in intellectualized collection development. Collection Building, 32(1), 4-11. doi:10.1108/01604951311295049

Ellis, J., \& Phillips, A. (2013). Re-defining the service experience: Forging collaboration between librarians and students. Library Management, 34(8/9), 603-618. doi:10.1108/LM10-2012-0070

Hines, E., \& Hines, S. (2012). Faculty and librarian collaboration on problem-based learning. Journal of Library Innovation, 3(2), 18-32.

Holloway, K. (2011). Outreach to distance students: A case study of a new distance librarian. Journal of Library \& Information Services in Distance Learning, 5(1-2), 25-33. doi:10.1080/1533290X.2011.548231

Koelker, J., Bouchard, K., \& Lutz, J. (2010). Development of the information commons at TCU: A case study. Journal of Library Administration, 50(2), 95-115. doi:10.1080/01930820903455032

Kopp, M. G. (2013). Academic libraries, institutional missions, and new student recruitment: A case study. Reference Services Review, 41(2), 192-200. doi:10.1108/00907321311326192

Laster, S., Stitz, T., Bove, F. J., \& Wise, C. (2011). Transitioning from marketing-oriented design to user-oriented design: A case study. Journal of Web Librarianship, 5(4), 299-321. doi:10.1080/19322909.2011.623517 
Leong, J., \& Nguyen, L. H. (2011). Continuing professional development for RMIT International University Vietnam library staff: Adding value through an international partnership: A case study. The International Information \& Library Review, 43(3), 169-175. doi:10.1016/j.iilr.2011.07.008

Mandel, L.H., (2013). Finding their way: How public library users wayfind. Library \& Information Science Research, 35(4), pp.264-271. Available at: http://www.sciencedirect.com/science/article/pii/S0740818813000613.

Martin, J. A. (2010). A case study of academic library and economic development center collaboration at the University of Toledo. Journal of Business \& Finance Librarianship, 15(3-4), 237-252. doi:10.1080/08963568.2010.490059

Mazella, D., \& Grob, J. (2011). Collaborations between faculty and special collections librarians in inquiry-driven classes. Libraries and the Academy, 11(1), 467-487.

Mix, V. L. (2013). Library and university governance: Partners in student success. Reference Services Review, 41(2), 253-265. doi:10.1108/00907321311326219

Murray, A. (2011). Maximizing an economic recession through strategic organizational repositioning. The Bottom Line, 24(1), 13-23. doi:10.1108/08880451111142006

Sargent, A. R., Becker, B. W., \& Klingberg, S. (2011). Incorporating library school interns on academic library subject teams. The Journal of Academic Librarianship, 37(1), 28-33. doi:10.1016/j.acalib.2010.10.004

Soules, A., Nielsen, S., Lee, H. Y., \& Rifae, K. A. (2013). Embedding information literacy in an MA TESOL program. New Library World, 114(1/2), 32-43. doi:10.1108/03074801311291947 
Sugie, N., (2013). Application of radio frequency identification technology to study library users' information-seeking behavior. Library \& Information Science Research, 35(1), pp 69-77. Available at: http://www.sciencedirect.com/science/article/pii/S0740818812000953

Washburn, A., \& Bibb, S. (2011), Students studying students: An assessment of using undergraduate student researchers in an ethnographic study of library use, Library and Information Research, 35(109), 55-66.

Zaugg, H., Child, C., Roberts, B., Alexander, A., Christensen, M., Ellsworth, E., Fritzler, M., Hamilton, K., Hansen, E., Markel, R., Moffett, S., Morris, S., Peterson, T., Reid, T., Wease, W. and Waggener, B. (2015, July). Long-term qualitative analysis of LibQUAL+® comments in an academic library, 2003-2013. Paper presented at the 11thNorthumbria Conference, Edinburgh, Scotland.

Zaugg, H., Rackham, S., Davis, M., Bleggi, J., Grout, A., Boehme, A., Carter, C., Brooks, C., McOmber, C., Douglas, L., Valentine, J., Stucki, S., Meacham, G., Clark, B., Coles, E., Dastrup, B., Miligan, R., and Whit, J. (2015, July). Identification and development of patron personas for an academic library. Paper presented at the 11thNorthumbria Conference, Edinburgh, Scotland. 